\title{
Prevalence of chronic bronchitis in an industrial population in North India
}

\author{
R. C. JOSHI, R. N. MADAN, and A. A. B RASH \\ Walsall General Hospital, Walsall, Staffs, UK and Department of Medicine, \\ Christian Medical College and Hospital, Ludhiana, Punjab, India
}

\begin{abstract}
Joshi, R. C., Madan, R. N., and Brash, A. A. (1975). Thorax, 30, 61-67. Prevalence of chronic bronchitis in an industrial population in North India. A survey for the prevalence of chronic bronchitis in an industrial population in North India is reported. The prevalence of chronic bronchitis is $12.5 \%$ in 473 subjects between the ages of 17 and 64 years. The prevalence rate of chronic bronchitis is comparable to that observed in areas of low community air pollution in Europe and North America. There is no agerelated rise in the frequency of respiratory symptoms.

The consumption of tobacco in these subjects is low and is comparable to tobacco consumption of light smokers. The prevalence of chronic bronchitis in smokers is five times the prevalence in non-smokers and is similar to the values reported for light smokers in other surveys. These observations suggest that cigarette smoking is associated with the development of chronic bronchitis, and the differences in the prevalence rate of chronic bronchitis between this survey and other surveys conducted in Europe and North America are mainly due to differences in smoking habits. Air pollution has a minor effect only and ethnic differences do not appear to play any part.

Forced expired volume in one second shows a negative correlation with age. It is lower in asymptomatic smokers than in non-smokers and is lower in chronic bronchitis than in controls.
\end{abstract}

Chronic bronchitis has been recognized as a major public health problem in the United Kingdom since 1950. In fact it has been called 'the English disease'. With the standardization of diagnostic and epidemiological methods, comparative international studies in the last decade have shown chronic bronchitis to occur throughout Europe and North America (Fletcher, 1963; Mork, 1964).

There are, however, geographical variations in the prevalence of chronic bronchitis which persist even after accounting for the differences in smoking habits. These variations have been explained by variations in the level of community air pollution (Holland and Reid, 1965) and ethnic differences (Ferris and Anderson, 1962; Coates, Bower, and Reinstein, 1965; Massaro, Cusick, and Katz, 1965).

Adequate epidemiological data on the prevalence of chronic bronchitis on the Indian subcontinent are lacking. It is the general impression of clinicians that the prevalence of chronic bronchitis in North India is fairly high. Wig (1960) found that during the period $1952-54$ over $30 \%$ of patients reporting to the Chest Clinic in Amritsar were suffering from chronic bronchitis. Viswanathan and Jain (1963) report that in 1961 over $20 \%$ of all patients attending the Chest Institute, Delhi were diagnosed as having chronic bronchitis.

The purpose of this study is to survey the prevalence of chronic bronchitis in industrial workers of a town in North-West India, using methods comparable to those in other surveys.

\section{MATERIAL AND METHODS}

The survey was located in Ludhiana, a town with a population of approximately 0.45 million, in NorthWest India. It is $225 \mathrm{~m}$ above sea level, with a mean temperature of $12^{\circ} \mathrm{C}$ in January and $35^{\circ} \mathrm{C}$ in July. Mean annual precipitation is $60 \mathrm{~cm}$. There is very little air pollution. There are a large number of smallscale industries which run on electricity and do not contribute significantly to air pollution. The only source of air pollution is the smoke produced from the burning of coal and firewood used as fuel for 
cooking and, to some extent, for domestic heating in the winter.

The employees of a machine tool factory and a woollen hosiery mill, a total of 486 men, were chosen for the survey. The nature and purpose of the survey were explained to the subjects who were asked to volunteer. One of the investigators (RNM) personally interviewed the subjects regarding their respiratory symptoms. A translated short MRC questionnaire on chronic bronchitis (Medical Research Council, 1960) was used with particular emphasis on the following questions:

1. Do you usually cough up phlegm from your chest (not from the back of your nose)? Those who answered 'no' were asked if they brought up phlegm at all on getting up (or first thing in the morning).

2. How long have you had this cough and/or phlegm (two years or more)?

The subjects had a complete clinical examination and a $70 \mathrm{~mm}$ chest radiograph. Minifilms were read independently by one of the investigators (RCJ) and a radiologist. A third reading of the film was made when the interpretation was not agreed. A standard chest film was obtained if the minifilm showed any cardiac or lung abnormality.

After two practice runs, three recordings of the forced expiratory spirogram (FES) were made in a sitting position on a 9-litre Collins spirometer. Forced expiratory volume in one second $\left(F_{E V} V_{1.0}\right)$ was obtained from these traces, the starting point for the measurement being $200 \mathrm{ml}$ below peak inspiration (Kory, Callahan, Boren, and Syner, 1961). The best of the three readings was accepted, and the volume was converted to body temperature and pressure, saturated with water vapour.

STATISTICAL METHODS The regressions of FEV $_{1.0}$ on age were obtained by the method of least squares. An analysis of covariance was done on these regressions. The significance of difference between the two proportions was tested by the $\mathrm{z}$ test. Student's $t$ test was used to test the significance of difference between the two means.
DEFINITIONS Chronic bronchitis (CB) is defined as production of phlegm from the chest on most days for at least three months in a year for at least two years in the absence of other causative diseases (Ciba् Guest Symposium, 1959).

Asthma is defined as abnormal and paroxysmabo breathlessness associated with wheezing (Ciba Guest? Symposium, 1959).

'Other respiratory symptoms' (ORS) are defined as' upper respiratory symptoms not satisfying the criterify for the diagnosis of chronic bronchitis, such as fre quent nasal catarrh, sinusitis, and unproductiv $\underset{\alpha}{ }$ cough.

A cigarette smoker is defined as one who has smoked as much as one cigarette per day for as longis as one year (Doll and Hill, 1950).

\section{RESULTS}

Four hundred and seventy-three of 486 employeesD of the two industries between the ages of 17 and 64 years were available for the survey. The pre valence of chronic bronchitis and other respiratory and cardiac conditions, according to age and smoking habits, are given in Table $\mathbf{I}$.

Two hundred and ninety-four subjects had no respiratory symptoms and had a normal clinica examination and miniature chest film. They were used as controls for comparison with othe groups.

One hundred and sixty-two subjects had respira tory symptoms. Of these, 59 satisfied the criteria for the diagnosis of chronic bronchitis; 83 subjects were placed in the 'other respiratory symptoms group, and five subjects had bronchial asthma Fifteen subjects had radiologically active pul. monary tuberculosis, giving a prevalence rate of $3.2 \%$.

Cardiac lesions were found in seven subjects? Four had mitral stenosis, one had combined mitral and aortic stenosis, and two subjects had cardiac enlargement of undetermined aetiology.

T A B L E I

RESULTS OF SURVEY ACCORDING TO AGE AND SMOKING HABITS

\begin{tabular}{|c|c|c|c|c|c|c|c|c|}
\hline & \multirow[b]{2}{*}{ No. } & \multicolumn{5}{|c|}{ Age Distribution (years) } & \multicolumn{2}{|c|}{ Smoking Habit } \\
\hline & & $15-24$ & $25-34$ & $35-44$ & $45-54$ & $55-64$ & $\mathrm{Sm}$ & N.Sm \\
\hline $\begin{array}{l}\text { Normal controls } \\
\text { Chronic bronchitis } \\
\text { ORS group } \\
\text { Bronchial asthma } \\
\text { Pulmonary tuberculosis } \\
\text { (radiologically active) } \\
\text { Cardiac lesions } \\
\text { Other lesions }\end{array}$ & $\begin{array}{r}294 \\
59 \\
83 \\
5 \\
15 \\
7 \\
7 \\
10\end{array}$ & $\begin{array}{r}134 \\
16 \\
37 \\
1 \\
2 \\
5 \\
1\end{array}$ & $\begin{array}{r}113 \\
32 \\
35 \\
2 \\
5 \\
2 \\
2\end{array}$ & $\begin{array}{r}24 \\
5 \\
8 \\
1 \\
1 \\
-3\end{array}$ & $\begin{array}{r}15 \\
4 \\
2 \\
1 \\
3 \\
-1\end{array}$ & $\begin{array}{r}8 \\
2 \\
1 \\
4 \\
-3\end{array}$ & $\begin{array}{r}124 \\
50 \\
58 \\
2 \\
5 \\
1 \\
1 \\
4\end{array}$ & $\begin{array}{r}170 \\
9 \\
25 \\
3 \\
10 \\
6 \\
6\end{array}$ \\
\hline Total & 473 & 196 & 191 & 42 & 26 & 18 & 244 & 229 \\
\hline $\begin{array}{l}\text { Male population of India } \\
\text { (millions) }\end{array}$ & & $36 \cdot 8$ & $34 \cdot 5$ & $25 \cdot 7$ & $18 \cdot 9$ & $11 \cdot 0$ & & \\
\hline
\end{tabular}

Sm $=$ current cigarette smoker N.Sm = never smoked. 
Miscellaneous radiological and/or clinical abnormalities were found in 10 subjects. Seven subjects showed radiological evidence of minimal to moderate generalized pulmonary fibrosis, one had marked kyphoscoliosis, one had pleural effusion/thickening, and one had a large calcified shadow in the lung.

There were 244 smokers $(51.6 \%)$ and 229 nonsmokers $(48.4 \%)$ in this sample. None of the subjects smoked 20 cigarettes or more daily. There were no pipe or cigar smokers.

Only subjects with respiratory symptoms, with the exclusion of bronchial asthma and pulmonary tuberculosis, are used in further analyses.

PREVALENCE OF CHRONIC BRONCHITIS The percentage prevalence of chronic bronchitis according to 10-year age groups and smoking habits is shown in the Figure. The overall prevalence of chronic bronchitis in this population is $12.5 \%$.

Age The prevalence of chronic bronchitis rises significantly from $8.2 \%$ in the 15-24-year age group to $16.8 \%$ in the 25-34-year age group $(\mathbf{P}<0.01)$. There is no statistically significant change in prevalence in the subsequent age groups.

Smoking The prevalence of chronic bronchitis is $20.5 \%$ in smokers and $3.9 \%$ in non-smokers. The difference is highly significant $(P<0.001)$. It was not possible to analyse the effect of increasing tobacco consumption as none of the subjects smoked more than 20 cigarettes per day and only five subjects with chronic bronchitis smoked more than 14 cigarettes per day.

PULMONARY FUNCTION TESTS Table II gives the mean, range, standard deviation, and regressions on age of $\mathrm{FEV}_{1 \cdot 0}$ in normal controls, chronic bronchitics, and subjects with 'other respiratory symptoms'. Table III gives the mean and range of FEV ${ }_{1.0}$ in each age group of these subjects.

The $\mathrm{FEV}_{1.0}$ shows a significant negative regression with age in each of three clinical groups. An analysis of covariance was done on regressions of $\mathrm{FEV}_{1 \cdot 0}$ on age. The effect of cigarette smoking and of respiratory symptoms on $\mathrm{FEV}_{1.0}$ could then be analysed by excluding the effect of age on FEV $_{1 \cdot 0}$.

Smoking The effect of smoking on the FEV 1.0 was assessed in the control group. Of 294 subjects, 170 are non-smokers $(56.8 \%)$ and $124(43.2 \%)$ cigarette smokers. The mean $\mathrm{FEV}_{1.0}$ of nonsmokers is 3.03 litres and is significantly higher than the mean $\mathrm{FEV}_{1.0}$ of 2.89 litres in smokers $(P<0.02)$. Covariance analysis shows a significant difference in the regressions of $\mathrm{FEV}_{1.0}$ on age in these groups $(P<0.05)$.

告

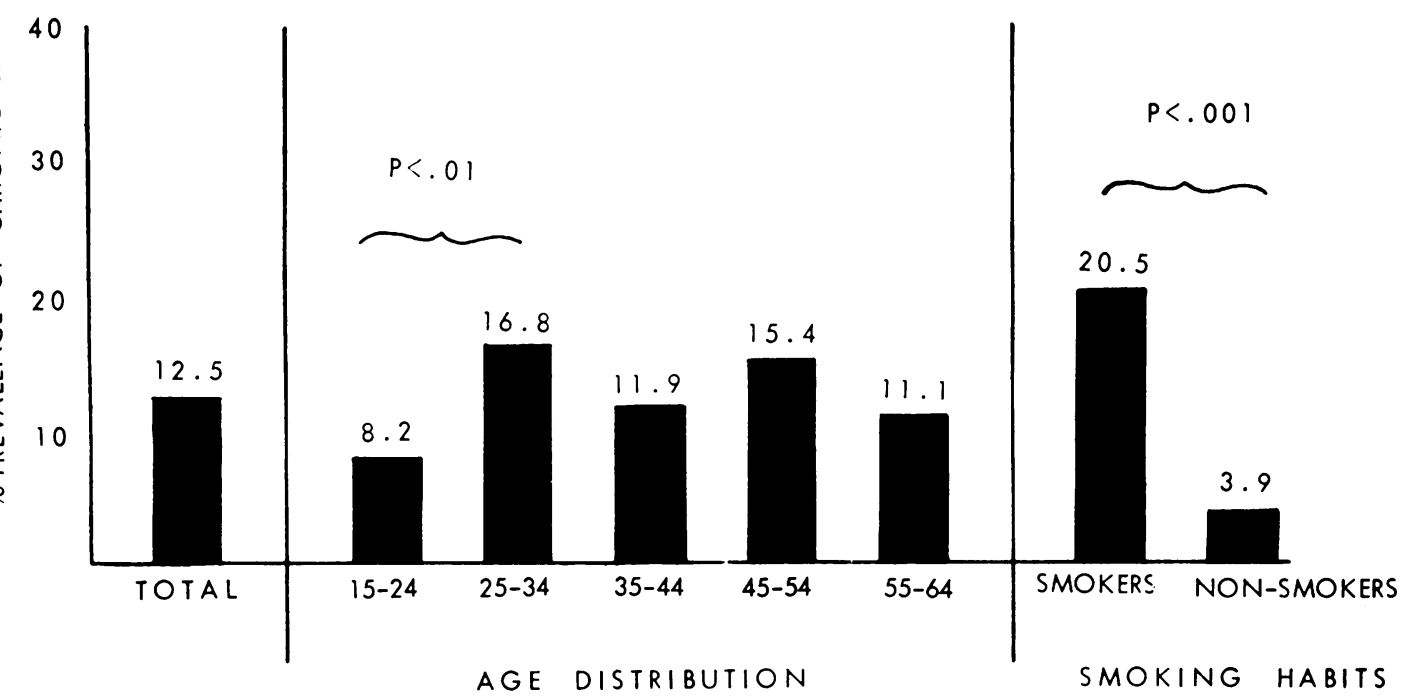

FIGURE Prevalence (percent) of chronic bronchitis according to age and smoking habits. 
T A B L E I I

FORCED EXPIRATORY VOLUME, ONE SECOND $\left(\mathrm{FEV}_{1 \cdot 0}\right)$

\begin{tabular}{|c|c|c|c|c|c|c|c|c|}
\hline & \multirow[b]{2}{*}{ No. } & \multirow[b]{2}{*}{ Mean (1.) } & \multirow[b]{2}{*}{ Range (1.) } & \multirow[b]{2}{*}{ SD } & \multicolumn{4}{|c|}{ Regressions on Age } \\
\hline & & & & & Slope & Intercept & $\mathbf{r}$ & SEE \\
\hline $\begin{array}{l}\text { Normal controls } \\
\text { Non-smokers } \\
\text { Smokers } \\
\text { Chronic bronchitis } \\
\text { ORS group }\end{array}$ & $\begin{array}{r}294 \\
170 \\
124 \\
59 \\
83\end{array}$ & $\begin{array}{l}2 \cdot 97 \\
3 \cdot 03 \\
2 \cdot 89 \\
2 \cdot 70 \\
2 \cdot 93\end{array}$ & $\begin{array}{l}1 \cdot 38-4 \cdot 44 \\
1 \cdot 38-4 \cdot 44 \\
1 \cdot 46-4 \cdot 05 \\
1 \cdot 34-4 \cdot 54 \\
1 \cdot 33-4 \cdot 09\end{array}$ & $\begin{array}{l}0.497 \\
0.490 \\
0.494 \\
0.600 \\
0.552\end{array}$ & $\begin{array}{r}-0.020 \\
-0.022 \\
-0.018 \\
-0.026 \\
-0.032\end{array}$ & $\begin{array}{l}3 \cdot 545 \\
3 \cdot 631 \\
3 \cdot 388 \\
3 \cdot 477 \\
3 \cdot 792\end{array}$ & $\begin{array}{r}-0.398 \\
-0.449 \\
-0.324 \\
-0.414 \\
-0.474\end{array}$ & $\begin{array}{l}0.456 \\
0.439 \\
0 \cdot 470 \\
0.551 \\
0.489\end{array}$ \\
\hline
\end{tabular}

T A B L E I I I

MEAN FEV $_{1 \cdot 0}$ (litres) ACCORDING TO AGE GROUP

\begin{tabular}{|c|c|c|c|c|c|}
\hline & \multicolumn{5}{|c|}{ Age Group (years) } \\
\hline & $15-24$ & $25-34$ & $35-44$ & $45-54$ & $55-64$ \\
\hline $\begin{array}{l}\text { Normal controls } \\
\text { Non-smokers } \\
\text { Smokers } \\
\text { Chronic bronchitis } \\
\text { ORS group }\end{array}$ & $\begin{array}{c}3 \cdot 14 \\
(2 \cdot 00-4 \cdot 44) \\
3 \cdot 18 \\
(2 \cdot 33-4 \cdot 44) \\
3 \cdot 07 \\
(2 \cdot 00-4 \cdot 05) \\
2 \cdot 88 \\
(1 \cdot 74-3 \cdot 70) \\
3 \cdot 11 \\
(2 \cdot 28-4 \cdot 09)\end{array}$ & $\begin{array}{c}2 \cdot 92 \\
(1 \cdot 38-4 \cdot 08) \\
3 \cdot 03 \\
(1 \cdot 38-4 \cdot 08) \\
2 \cdot 80 \\
(2 \cdot 04-3 \cdot 75) \\
2 \cdot 82 \\
(1 \cdot 88-4 \cdot 54) \\
2 \cdot 88 \\
(1 \cdot 53-3 \cdot 74)\end{array}$ & $\begin{array}{c}2 \cdot 75 \\
(2 \cdot 04-3 \cdot 87) \\
2 \cdot 72 \\
(2 \cdot 04-3 \cdot 19) \\
2 \cdot 77 \\
(2 \cdot 08-3 \cdot 87) \\
1 \cdot 99 \\
(1 \cdot 34-2 \cdot 23) \\
2 \cdot 77 \\
(2 \cdot 25-3 \cdot 12)\end{array}$ & $\begin{array}{c}2 \cdot 73 \\
(1 \cdot 93-3 \cdot 29) \\
2 \cdot 64 \\
(1 \cdot 93-2 \cdot 91) \\
2 \cdot 98 \\
(2 \cdot 71-3 \cdot 29) \\
2 \cdot 20 \\
(1 \cdot 49-2 \cdot 89) \\
1 \cdot 66 \\
(1 \cdot 33-1 \cdot 99)\end{array}$ & $\begin{array}{c}2 \cdot 07 \\
(1 \cdot 46-2 \cdot 65) \\
2 \cdot 15 \\
(1 \cdot 73-2 \cdot 65) \\
1 \cdot 95 \\
(1 \cdot 46-2 \cdot 60) \\
2 \cdot 09 \\
(2 \cdot 07-2 \cdot 11) \\
1 \cdot 36 \\
\left(\begin{array}{c}1 \\
-\end{array}\right)\end{array}$ \\
\hline
\end{tabular}

Figures in parentheses are the range.

Respiratory symptoms The mean $\mathrm{FEV}_{1.0}$ of 2.97 litres in normal controls is significantly higher that the mean $\mathrm{FEV}_{1.0}$ of 2.70 litres in chronic bronchitics $(\mathrm{P}<0.001)$. The regressions of FEV $_{1.0}$ on age in the two groups also show a significant difference on covariance analysis $(\mathbf{P}<0.01)$.

The ORS group has a significantly higher FEV $_{1.0}(2.93$ litres) than the chronic bronchitis group $(P<0.05)$. However, the difference in the regressions of $\mathrm{FEV}_{1.0}$ on age is not statistically significant.

There is no significant difference in $\mathrm{FEV}_{1.0}$ between normal controls and subjects of the ORS group.

\section{DISCUSSION}

Various population groups have been surveyed for the prevalence of chronic bronchitis in different countries. These include the randomly selected general population of a town, city or county (Gocke and Duffy, 1962; Anderson, Ferris, and Zickmantel, 1965a; Rimington, 1969), hospital in-patients (Massaro et al., 1965), and special occupational groups such as post office employees (Fletcher, Elmes, Fairbairn, and Wood, 1959; Coates et al., 1965), transport workers (Holland and Reid, 1965), and workers in various industries (Sharp et al., 1965). A hospi $\frac{2}{2}$ tal population is biased by the mere fact that it is $\vec{B}$ hospitalized. Although a survey of the entire population is ideal, surveying special occupationa groups such as an industrial population has its. advantages. Such a population is relatively stable and can easily be approached and standardized. $\frac{\circ}{2}$

The radiological screening of subjects has not been a standard procedure in surveys for the prevalence of chronic bronchitis in Europe anके North America. This has been justified as the prevalence of tuberculosis is quite low. The average prevalence of radiologically active tuber-5 culosis in India was found to be $1.8 \%$ on $\frac{7}{2}$ national survey in 1955-58 (Deshmukh, 1970) The prevalence rate of radiologically actives tuberculosis in this survey is higher than the national average for India. This fact underlines the importance of radiological screening in surs veys for respiratory symptoms in populatione groups with a high prevalence of pulmonarye tuberculosis.

Most of the prevalence surveys for chronic ${ }^{?}$ bronchitis are on the population above the age of 40 years. A few surveys which have includede्त subjects under 40 years of age show a significant?

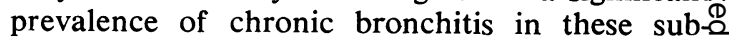
jects (Ferris and Anderson, 1962; Payne and Kjelsberg, 1964; Anderson et al., 1965a). 
In this study all subjects regardless of their ages are included. There is a preponderance of younger subjects in the sample, a trend which is, to some extent, reflected in the age distribution of the male population of India between the ages of 15 and 64 years (Research and Reference Division, Ministry of Information and Broadcasting, Government of India, 1971) (Table I).

The results of the present survey are consistent with the well recognized observation that the $\mathrm{FEV}_{1 \cdot 0}$ decreases with age and that it is lower in asymptomatic smokers than in non-smokers. $\mathrm{FEV}_{1.0}$ is also significantly lower in subjects who produce phlegm than in asymptomatic controls, and this difference persists when the effect of age is taken into account.

PREVALENCE OF CHRONIC BRONCHITIS: COMPARISON WITH OTHER SURVEYS Table IV gives the salient features of a few surveys on the prevalence of chronic bronchitis which have used definitions and methods comparable to the present survey. The prevalence of chronic bronchitis in this survey is $12.5 \%$, which is comparable to the prevalence observed in a few areas of relatively low community air pollution (Olsen and Gilson, 1960; Payne and Kjelsberg, 1964; Sharp et al., 1965; Rimington, 1969).

There is no significant trend towards a rise in the prevalence of chronic bronchitis with age. A similar lack of relationship between age and prevalence rate of chronic bronchitis is observed in a number of surveys conducted in North America (Table IV). Read and Selby (1961), too, showed a lack of age gradient in the prevalence of chronic bronchitis in Australia.

However, various surveys in Great Britain show a rise in the frequency of cough and phlegm with age (Fletcher et al., 1959; Higgins, 1959; Holland and Reid, 1965; Rimington, 1969). Air pollution may be one of the factors which may cxplain the age gradient of chronic bronchitis in these surveys. In a survey on postal employees in London by Fletcher et al. (1959), females who are less exposed to atmospheric pollution do not show a definite age-related rise in respiratory symptoms. Holland and Reid (1965) observe a positive relationship between age and chronic bronchitis in London but not in county towns with low levels of air pollution.

The relationship between smoking and chronic bronchitis is now well established by many epidemiological surveys (Royal College of Physicians of London, 1962; United States Public Health Service, 1964). The proportion of cigarette smokers in the present sample is low when compared with the populations surveyed in Europe and North America (Table IV). A greater difference is seen when the amount of tobacco consumption is compared. This difference is also reflected in the national figures of cigarette consumption per adult per annum in 1970, which are 190 for India, 3,670 for the USA, 3,340 for Canada, and 3,050 for the UK (Tobacco Research Council, 1972).

Most of the investigators classify subjects smoking one to 14 cigarettes per day as light smokers (Fletcher et al., 1959; Higgins, 1959; Anderson, Ferris, and Zickmantel, 1965b; Holland and Reid, 1965; Holland and Stone, 1965). By this criterion the subjects of the present sample can be regarded as light smokers. However, smokers show a five times increase in the frequency of cough and phlegm when compared with non-smokers. This is in accord with the observations of Read and Selby (1961) and Gocke and Duffy (1962) that the greatest increase in the prevalence of chronic bronchitis is at the 'threshold' between smokers and non-smokers.

A comparison of the smokers in this study with the subjects of other surveys with comparable smoking habits shows a close agreement in the prevalence of chronic bronchitis (Table IV). Smoking is thus by far the most important factor associated with chronic bronchitis and greatly outweighs the effect of other factors such as community air pollution. These observations suggest that the differences in the prevalence rate of chronic bronchitis between this population group and the population groups in other geographical areas and climates may be related to differences in smoking habits. Air pollution seems to play only a minor part, and it is unlikely that ethnic differences are of any significance.

The writers thank Professor J. M. Bishop, Department of Medicine, Queen Elizabeth Hospital, Birmingham, for useful suggestions in the preparation of the manuscript; Mr. D. Barer, M.Sc., for assistance with the statistical analysis of data; and Dr. C. V. Hartman, consultant radiologist, Christian Medical College and Hospital, Ludhiana, for interpretation of the radiographs.

\section{REFERENCES}

Anderson, D. O., Ferris, B. G. Jr., and Zickmantel, R. (1965a). The Chilliwack respiratory survey, 1963; III. The prevalence of respiratory disease in a rural Canadian town. Canadian Medical Association Journal, 92, 1007. 


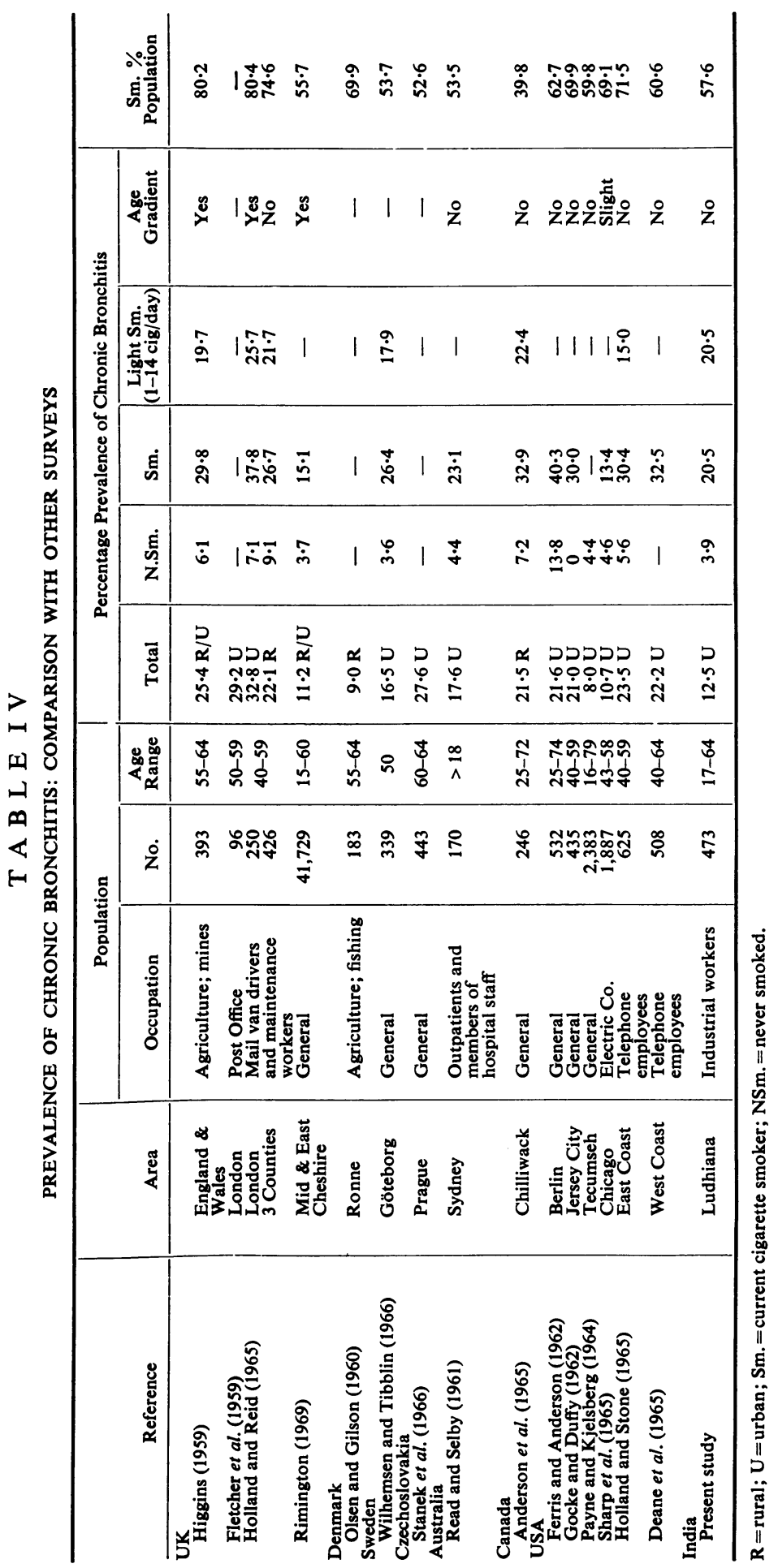


(1965b). The Chilliwack respiratory survey, 1963; IV. The effect of tobacco smoking on the prevalence of respiratory disease. Canadian Medical Association Journal, 92, 1066.

Ciba Guest Symposium (1959). Terminology, definitions, and classification of chronic pulmonary emphysema and related conditions. A report of the conclusions of a Ciba Guest Symposium. Thorax, 14, 286.

Coates, E. O. Jr., Bower, G. C., and Reinstein, N. (1965). Chronic respiratory disease in postal employees. Journal of the American Medical Association, 191, 161.

Deane, M., Goldsmith, J. R., and Tuma, D. (1965). Respiratory conditions in outside workers. Archives of Environmental Health, 10, 323.

Deshmukh, M. D. (1970). Tuberculosis. Journal of the Association of Physicians of India, 18, 105.

Doll, R. and Hill, A. B. (1950). Smoking and carcinoma of the lung. British Medical Journal, 2, 739.

Ferris, B. G. Jr. and Anderson, D. O. (1962). The prevalence of chronic respiratory disease in a New Hampshire town. American Review of Respiratory Diseases, 86, 165.

Fletcher, C. M. (1963). An account of chronic bronchitis in Great Britain with a comparison between British and American experience of the disease. Diseases of the Chest, 44, 1.

Elmes, P. C., Fairbairn, A. S., and Wood, C. H. (1959). The significance of respiratory symptoms and the diagnosis of chronic bronchitis in a working population. British Medical Journal, 2, 257.

Gocke, T. M. and Duffy, B. J. (1962). Epidemiology of chronic bronchitis in Jersey City. Archives of Internal Medicine, 110, 606.

Higgins, I. T. T. (1959). Tobacco smoking, respiratory symptoms, and ventilatory capacity. British Medical Journal, 1, 325.

Holland, W. W. and Reid, D. D. (1965). The urban factor in chronic bronchitis. Lancet, 1, 445.

and Stone, R. W. (1965). Respiratory disorders in United States east coast telephone men. American Journal of Epidemiology, 82, 92.

Kory, R. C., Callahan, R., Boren, H. G., and Syner, J. C. (1961). The Veterans AdministrationArmy Co-operative study of pulmonary function. I. Clinical spirometry in normal men. American Journal of Medicine, 30, 243.

Massaro, D., Cusick, A. M., and Katz, S. (1965). Racial differences in incidence of chronic bronchitis. American Review of Respiratory Disease, 92, 94.

Medical Research Council. (1960). Medical Research Council's Committee on the aetiology of chronic bronchitis: Standardized questionaries on respiratory symptoms. British Medical Journal, 2, 1665.

Mork, T. (1964). International comparisons of the prevalence of chronic bronchitis. Proceedings of the Royal Society of Medicine, 57, 975.
Olsen, H. C. and Gilson, J. C. (1960). Respiratory symptoms, bronchitis, and ventilatory capacity in men. An Anglo-Danish comparison, with special reference to differences in smoking habits. British Medical Journal, 1, 450.

Payne, M. and Kjelsberg, M. (1964). Respiratory symptoms, lung function, and smoking habits in an adult population. American Journal of Public Health, 54, 261.

Read, J. and Selby, T. (1961). Tobacco smoking and ventilatory function of the lungs. British Medical Journal, 2, 1104.

Research and Reference Division, Ministry of Information and Broadcasting, Government of India. (1971). India: A Reference Annual, 197172, Ch. 1, p. 12. Publications Division, Ministry of Information and Broadcasting, Government of India.

Rimington, J. (1969). Chronic bronchitis, smoking and social class. A study among working people in the towns of Mid and East Cheshire. British Journal of Diseases of the Chest, 63, 193.

Royal College of Physicians of London. (1962). Smoking and Health. Summary and a Report of the Royal College of Physicians of London on Smoking in relation to Cancer of the Lung and Other Diseases. Pitman, London.

Sharp, J. T., Paul, O., Lepper, M. H., McKean, H., and Saxton, G. A. Jr. (1965). Prevalence of chronic bronchitis in an American male urban industrial population. American Review of Respiratory Diseases, 91, 510.

Stanek, V., Fodor, J., Hejl., Z., Widimsky, J., Charvat, P., Santrucek, M., Zajic, F., and Vavrik, M. (1966). A contribution to the epidemiology of chronic bronchitis. Acta Medica Scandinavica, 179, 737.

Tobacco Research Council. (1972). Tobacco Consumption in Various Countries. Research Paper 6 , 3rd ed., edited by D. H. Beese, p. 4. Tobacco Research Council, London.

United States Public Health Service. (1964). Smoking and Health; Report of the Advisory Committee to the Surgeon General of the Public Health Service. Public Health Service Publication No. 1103. Superintendent of Documents, Printing Office, Washington, D.C.

Viswanathan, R. and Jain, S. K. (1963). Aerohaemodynamic studies in chronic bronchopulmonary diseases. Indian Journal of Chest Diseases, 5, 68.

Wig, K. L. (1960). Editorial: Chronic bronchitis and emphysema. Indian Journal of Chest Diseases, 2,60 .

Wilhelmsen, L. and Tibblin, G. (1966). Tobacco smoking in fifty-year-old men. I. Respiratory symptoms and ventilatory function tests. Scandinavian Journal of Respiratory Diseases, 47, 121 .

Requests for reprints to: Dr. R. C. Joshi, Walsall General Hospital, Wednesbury Road, Walsall, Staffs. 